\title{
NAS TRILHAS DA TRADUÇÃO E INTERPRETAÇÃO DE PORTUGUÊS-LIBRAS EM REVISTAS DE TRADUÇÃO NO BRASIL
}

\author{
Silvana Aguiar dos Santos \\ Mairla Pereira Pires Costa \\ Thuanny Sá Galdino
}

\begin{abstract}
RESUMO
Este trabalho descreve e analisa o percurso das publicações sobre tradução e interpretação de Português-Libras em algumas revistas de Tradução no Brasil. Os resultados constatam um total de 36 trabalhos publicados, distribuídos nas revistas de tradução de diferentes partes do país. Os temas considerados consagrados e aqueles que emergiram no período de 1990 a 2014 também foram examinados nessas publicaçóes.

PALAVRAS-CHAVE: Estudos da Tradução; Estudos da Tradução e Interpretação de Língua de Sinais; Produção acadêmica.
\end{abstract}

\section{Introdução}

1

o Brasil, a produção e disseminação do conhecimento sobre tradução e interpretação de língua de sinais têm sido cada vez mais evidentes, seja na multiplicação de textos acadêmicos que circulam em diversas revistas brasileiras, seja na presença de pesquisadores inseridos nos programas de pós-graduação em nosso país. Nesse sentido, o Programa de Pós-Graduação em Estudos da Tradução (PGET) da Universidade Federal de Santa Catarina (UFSC) tem se destacado como um polo articulador das açóes que envolvem os Estudos da Tradução e Interpretação de Língua de Sinais (ETILS) e os Estudos da Tradução. 
Um exemplo disso são as várias teses e dissertaçóes em andamento e as defendidas junto ao Programa desde 2010 e a existência de uma linha de pesquisa denominada Estudos da Interpretação, que tem acolhido uma série de pesquisas sobre interpretação de língua de sinais. Além disso, o ingresso de professores ouvintes e surdos da subárea de ETILS junto ao PGET qualifica a abrangência dos diversos temas tratados nas pesquisas e aumenta o escopo dos objetos investigados nos Estudos da Tradução. Todas essas ações contribuem para que a produção acadêmica de ETILS seja cada vez mais visível, e ratifique a articulação possível e necessária dessa subárea junto aos Estudos da Tradução, à luz de publicaçóes internacionais já consagradas. Nesse trabalho tem-se o intuito de identificar e analisar a produçáo acadêmica sobre ETILS enunciada por um recorte de algumas revistas de tradução no Brasil.

Em termos metodológicos, esta pesquisa de caráter bibliográfico, orientou-se pela abordagem qualitativa de cunho historiográfico/documental, a qual explora, de acordo com Silveira e Córdova (2009, p. 31): "objetivação do fenômeno; hierarquização das açóes de descrever, compreender, explicar; precisão das relaçôes entre o global e o local em determinado fenômeno". Além disso, realizaram-se alguns diálogos no texto, com o viés historiográfico como método articulado aos Estudos da Tradução, uma vez que os instrumentos utilizados foram as fontes documentais no formato de revistas eletrônicas sobre tradução.

O corpus analisado nesse trabalho foi composto por oito revistas na área de tradução, publicadas especificamente no período analisado (de 1990 a 2014). O presente artigo está organizado da seguinte forma: contextualiza-se, na introdução, um panorama sobre aspectos relevantes dos ETILS e consideraçôes iniciais sobre a pesquisa; seguida da seção2, que trata das contribuiçôes da pesquisa documental nos Estudos da Tradução e nos ETILS. Posteriormente, apresentam-se, na seção 3, os procedimentos metodológicos adotados e, na seção 4, os resultados da pesquisa. Por fim, algumas consideraçóes finais são tecidas, sugerindo a revisão e expansão de mapeamentos nos Estudos da Tradução.

\section{As contribuições da pesquisa documental nos estudos da tradução e nos etils}

Em uma área recente de estudos, questionamentos, como: o que se pesquisa, quando determinados assuntos foram mais investigados, quais autores, 
quais as instituições e que metodologias foram empregadas em diferentes fontes documentais, podem se tornar frequentes interrogaçóes. Segundo Ferreira, as pesquisas de caráter bibliográfico são "sustentadas e movidas pelo desafio de conhecer o já construído e produzido para depois buscar o que ainda não foi feito" (2002, p. 259). Nessa perspectiva, a abordagem historiográfica oferece riquíssimas contribuições aos Estudos da Tradução e, por extensão, aos ETILS, uma vez que sistematiza percursos e cataloga dados, registros que somados a diferentes fontes podem estabelecer o diálogo entre os campos do saber.

No entanto, como alerta Pagano (2001), tomar a sistematização dos dados como tempo único e linear é um dos perigos de quem opta por pesquisas historiográficas. A necessidade de articular os resultados obtidos considerando os diferentes tempos históricos e de confrontá-los com diversas formas de registros documentais são decisões fundamentais para que o pesquisador desenvolva um papel crítico e uma visão ampla de suas investigaçôes e de suas análises. De acordo com Pagano (2001), constituem uma tarefa paradoxal para o pesquisador, pois

Temos, [...], uma atividade dupla de construção e desconstrução, que requer que se trabalhe com os dados que a história nos oferece, submetendo-os, todavia, a uma indagação que possa ampliar o material existente e apontar para novos caminhos a serem percorridos. A metodologia de investigação requer, portanto, um exame cuidadoso (PAGANO, 2001, p. 118).

A necessidade de ampliar as análises da produção acadêmica associada a conjunturas sociais, econômicas, culturais entre outras esferas, possibilita reflexões sob múltiplos olhares e concepções teóricas. Ainda que as pesquisas sobre ETILS no Brasil tenham crescido de forma veloz nos últimos anos, especialmente após o reconhecimento e a regulamentação da Lei LIBRAS no 10.436/2002, elas enfrentam um deslocamento teórico, pois a maioria da produção acadêmica concentrava-se na área da Educação. A interface entre a área da Educação e a área dos Estudos da Tradução é pouco explorada em nosso país, haja vista a rara circulação de textos acadêmicos que discutem perspectivas pedagógicas e aspectos tradutórios. Embora discutidas com pouca frequência (interface entre Educação e Estudos da Tradução) nos mapeamentos, coloca-se em jogo a necessidade de estudos sistematizados que analisem os contornos da produção acadêmica no país. 
Pesquisas dessa natureza colaboram para constatar quais áreas estão obsoletas ou emergem a partir de determinado período histórico ou, ainda, quais instituições, bibliografias, disciplinas, pesquisadores, temas e objetos de pesquisa estão em evidência durante certo momento. O levantamento detalhado das pesquisas, dos trabalhos e da produção acadêmica sobre tradução e interpretação em língua de sinais é uma contribuição significativa para pesquisadores da subárea ETILS, pois auxiliará na composição de um panorama global da produção acadêmica e poderá, ainda, revitalizar as demandas que emergem a partir do fluxo dos assuntos investigados em determinada área, além de constatar as concepçóes e/ou tendências acadêmicas que sustentam essas pesquisas.

Grbic (2007) trouxe resultados pontuais sobre mapeamento de ETILS a partir de categorias analisadas como: línguas, tipos de textos, autores, distribuição de temas. Metzger (2010) e Napier (2010) apresentaram levantamentos bibliométricos que privilegiavam dados estatísticos com vistas a quantificar os tipos de produção (teses, dissertaçóes, artigos, resumos e outros), os países onde estão distribuídas essas produçôes, os assuntos com maior índice de ocorrência em determinado período, entre outros aspectos. Todos esses resultados oferecem elementos à construção de uma cartografia, ou seja, à construção do mapa de como a subárea tem se movimentado ao longo dos anos.

Em nosso país, uma das primeiras pesquisas que realizou um levantamento de teses e dissertaçóes em ETILS foi Pereira (2010). Nesse importante estudo, os resultados constatados apontaram para as instituiçóes, as áreas, as universidades nas quais as teses e dissertaçóes tinham sido produzidas. Além disso, tal mapeamento mostrou os campos de pesquisa e os interesses dessas investigaçóes, ilustrando o percurso acadêmico de ETILS. No Brasil, o registro de pesquisas sobre ETILS, a partir do estado da arte, foi analisado sobre diferentes perspectivas: descrição e análise de metodologias em anais de congresso científico (ALBRES, 2014), descrição de teses e dissertaçóes (PEREIRA, 2008), análise de teses e dissertaçôes (SANTOS, 2013), estudo bibliométrico de publicaçóes internacionais e suas marcas no campo nacional com ALBRES e LACERDA (2013). Dito de outra forma, as pesquisas que colocam em destaque o estado da arte de uma determinada área, de acordo com Ferreira (2002),

[...] são reconhecidas por realizarem uma metodologia de caráter inventariante e descritivo da produção acadêmica e 
científica sobre o tema que busca investigar, à luz de categorias e facetas que se caracterizam enquanto tais em cada trabalho e no conjunto deles, sob os quais o fenômeno passa a ser analisado (FERREIRA, 2002, p. 258).

Neste sentido, é possível constatar que a produção acadêmica sobre ETILS foi mapeada por diferentes perspectivas e corpus de análise. No entanto, um vasto campo nos mapeamentos dessa subárea carece ser explorado: Como ETILS são representados em algumas revistas científicas da área de Estudos da Tradução em nosso país? Neste artigo, analisou-se o corpus selecionado e discorreram-se considerações sobre essa articulação, seus desafios e perspectivas que emergem desses espaços de produção acadêmica.

Uma contribuição significativa de pesquisas com essas características refere-se à possibilidade de expansão das áreas que constituem mapeamentos em Estudos da Tradução. Ou seja, a maioria dos contextos de atuação de tradutores e de intérpretes de língua de sinais, assim como as produçóes acadêmicas são registradas frequentemente sobre contextos comunitários. Tanto Rodrigues (2010) quanto Queiroz (2011) concorda com Carr et al. (1995), que afirmam ser o termo "community interpreting" (interpretação comunitária) definido como uma "interpretação que 'permite que pessoas não fluentes na(s) língua(s) oficial(is) de um país possam se comunicar com provedores de serviços públicos de forma a facilitar acesso igual e integral a serviços legais, médicos, educacionais, governamentais e serviços sociais". ${ }^{1}$

Esse contexto é pouco explorado na produção acadêmica dos Estudos da Tradução em nosso país. Tal constatação corrobora e reitera a premissa de que a língua de sinais pode oferecer elementos importantes a serem articulados e expandidos nos Estudos da Tradução, conforme constatam os resultados desse artigo. Desta forma, a próxima seção trata-se dos procedimentos metodológicos e, a seguir, da análise da produção acadêmica sobre ETILS, a fim de que tenhamos um panorama mais elaborado de áreas emergentes neste contexto. Por fim, dificuldades e desafios para a institucionalização dos ETILS afiliados aos Estudos da Tradução são apresentados neste artigo.

Tradução de Mylene Queiroz. Sem acesso à citação original em inglês. 


\section{Procedimentos metodológicos}

O respaldo metodológico desta pesquisa foi o de cunho qualitativo aliado à pesquisa documental. $\mathrm{O}$ corpus examinado foi constituído de oito revistas na área de tradução, a saber: Revista Brasileira de Tradutores, Belas Infiéis, Cadernos de Tradução, Traduzires, Tradterm, Scientia Traductionis, In-Traduçóes e Tradução em Revista. De acordo com Dias e Faleiros (2014), "É possível identificar os assuntos em voga numa determinada área do conhecimento por meio de revistas especializadas de publicação periódica, pois se trata de uma das melhores fontes para tomar conhecimento com essa produção" (DIAS e FALEIROS, 2014, p. 193).

Além disso, a escolha dessas revistas ocorreu principalmente pelo fato da maioria delas estarem relacionadas com algum programa de Pós-Graduação em Estudos da Tradução ou ainda terem uma longa trajetória de publicaçóes, como é o caso da Tradução em Revista ${ }^{2}$. As revistas Cadernos de Tradução, In-Traduçôes e Scientia Traductionis estão vinculadas ao PGET da Universidade Federal de Santa Catarina (UFSC). Traduzires e Belas Infiéis são revistas vinculadas ao Programa de Pós-Graduação em Tradução (POSTRAD) da Universidade de Brasília. A Tradução em Revista é uma publicação vinculada ao Departamento de Letras da Pontifícia Universidade Católica do Rio de Janeiro (PUC-Rio). TradTerm é uma Revista do Centro Interdepartamental de tradução e terminologia da Universidade de São Paulo (USP). Por fim, a revista Tradução \& Comunicação (Revista Brasileira de Tradutores) está vinculada ao Centro Universitário Anhanguera de São Paulo (antigo Centro Universitário Ibero-Americano - Unibero).

Os artigos publicados nas revistas selecionadas foram examinados considerando o período de 1990 a 2014, com base nas seguintes categorias de análise: título, autor, ediçãao (número e volume) e instituição de origem dos autores. O primeiro passo realizado foi o levantamento em todas as ediçóes das revistas mencionadas acima, dos artigos que tratavam de ETILS identificados pelo título do trabalho. Um dos critérios de refinamento dessa busca centrou-se na leitura dos resumos desses trabalhos. A seguir apresentar-se-ão os resultados constatados na presente pesquisa.

2 Para aprofundamento sobre as revistas especializadas de tradução conferir Dias e Faleiros (2014). 


\section{Resultados e discussões}

Os primeiros resultados com relação aos artigos publicados sobre a temática da tradução e interpretação de língua de sinais são visibilizados a partir da primeira década de dois mil. Algumas questôes contribuem para essa visibilidade tardia: (i) grande parte dos trabalhos publicados estavam hospedados na área da Educação, sendo este campo precursor nas pesquisas sobre tradução e interpretação de língua de sinais no contexto brasileiro; (ii) por outro lado, o próprio campo dos Estudos da Tradução em nosso país ainda carece de uma institucionalizaçáo mais intensa, embora alguns avanços foram constatados no documento de avaliação trienal da área (Letras e Linguística) no ano de 2013. O relatório de avaliação trienal 2013 divulgado pela Coordenação de Aperfeiçoamento de Pessoal de Nível Superior apresentou a questão do surgimento cada vez mais frequente de áreas e linhas de pesquisa voltadas à Tradução, à Escrita Criativa, à Leitura e ao Ensino de Literatura ${ }^{3}$. É evidente que essas razões em relação a recente institucionalização (Estudos da Tradução e ETILS) afetam os resultados desta pesquisa, uma vez que alguns dos programas de pós-graduação em Estudos da Tradução foram criados há pouco tempo, por exemplo, o POSTRAD. Nos resultados que apresentamos abaixo, há duas revistas ligadas ao POSTRAD, a saber: revista Traduzires e Belas Infiéis.

A revista Traduzires contou com três volumes publicados, sendo um no ano de dois mil e doze e dois no ano de dois mil e treze. No ano de dois mil e quatorze, não tivemos dados registrados de publicaçóes nessa revista. A revista Bela Infiéis, também ligada ao POSTRAD, manteve-se com duas publicaçóes regulares ao ano, desde dois mil e doze. Por outro lado, a revista Cadernos de Tradução, que apresenta maior índice de artigos publicados sobre tradução e interpretação de língua de sinais, foi criada no ano de mil novecentos e noventa e seis. Ou seja, temos a solidificação da revista Cadernos de Traduçáo, quando ainda não tínhamos a existência da PGET.

Alguns elementos contribuíram para que a revista Cadernos de Tradução tivesse essa visibilidade acentuada em relação às publicaçóes sobre ETILS, pois a partir do ano de dois mil e seis, na UFSC, iniciou-se o curso de graduação (Licenciatura em Letras-Libras) e logo, a seguir, no ano de dois mil e oito, o

3 Consultar informaçôes em: http://www.capes.gov.br/36-noticias/6908-capes-divulga-resultado-final-da-avaliacao-trienal-2013-apos-analise-de-recursos 
curso de graduação Bacharelado em Letras-Libras, este último destinado à formação de tradutores e de intérpretes de Português-Libras. É importante destacar que algumas das pesquisas desenvolvidas atualmente na PGET são de egressos do curso de Bacharelado em Letras-Libras. Outro fator que contribuiu para ascensão da área ETILS na revista Cadernos de Tradução foram as pesquisas de mestrado e doutorado desenvolvidas junto ao Programa a partir de 2010, além de uma edição especial de publicações nessa revista, sobre tradução e interpretação de língua de sinais no ano de 2010. Esses fatos fazem-nos compreender o espaço que a revista Cadernos de Tradução tem dedicado ao longo dos anos à produçáo acadêmica sobre ETILS.

A distribuição de artigos publicados nas oito revistas de tradução em nosso país pode ser observada na figura 1 que mostra a revista Cadernos de Traduçâo em destaque.

Figura 1 - Artigos publicados de 1990 a 2014

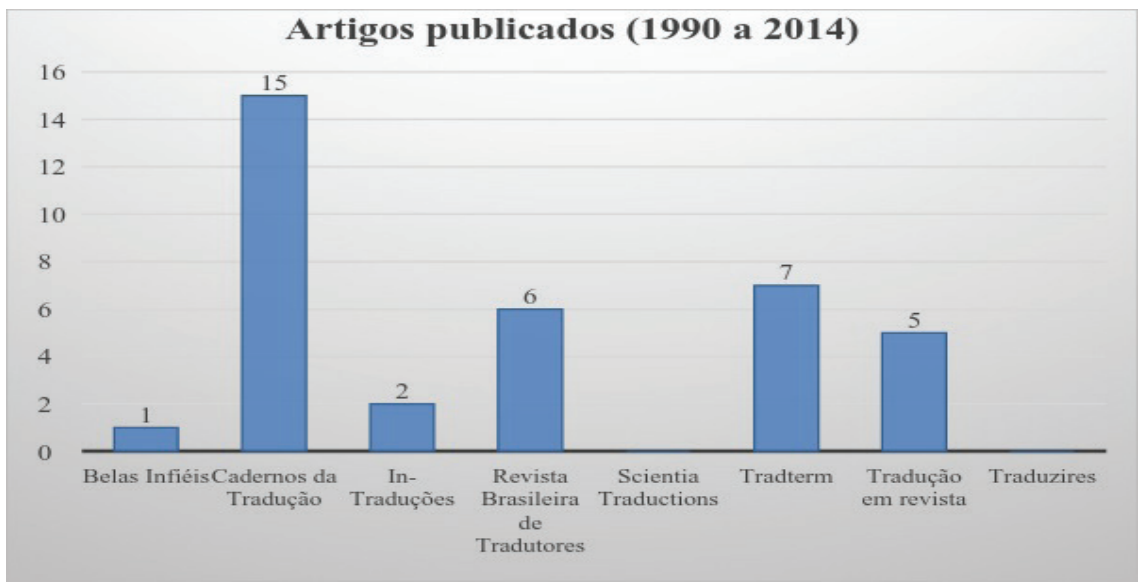

Fonte: próprios autores

Algumas iniciativas como dossiês temáticos sobre tradução audiovisual ou ainda sobre tradução e interpretação de língua de sinais contribuíram, significativamente, para alavancar a visibilidade das pesquisas nessa subárea. $\mathrm{Na}$ revista Cadernos de Tradução, temos uma variedade de temáticas registradas, como: interpretação comunitária (interpretação educacional, inclusão da pessoa surda 
e outros), produção acadêmica sobre interpretação de língua de sinais, formação de profissionais e pesquisadores, afiliação ao programa de pós-graduação, especificidades da interpretação de língua de sinais, poesia, glossários de termos técnicos e interpretação para surdos-cegos. Esses resultados constatados nas publicações brasileiras ratificam algumas das articulaçôes já registradas no campo internacional, trazidas especialmente por Williamns e Chestermann (2002). Os autores descreveram os tipos especiais de interpretação, incluindo interpretação para surdos-cegos, voice-over, legendagem e outros.

Por outro lado, na Revista Brasileira de Tradutores, na Revista Tradterm e na Tradução em Revista, conta-se com uma média de cinco a sete publicaçóes em cada uma delas, com perspectivas que ampliam as interfaces entre ETILS e Estudos da Tradução. Em comum, na revista Tradterm e na Tradução em Revista, a área de concentração dos artigos publicados foram a tradução audiovisual, abordando questóes como dublagem, legendagem, voice-over, acessibilidade e outros.

Na Revista Brasileira de Tradutores, há uma diversidade maior de temas que foram tratados, a saber: proficiência linguística dos intérpretes de língua de sinais, gêneros discursivos da esfera acadêmica e práticas de tradução e interpretação, construção e legitimação da identidade do intérprete, interpretação da Libras para o Português, entre outros. Na revista Belas Infiéis, a área representada foi a tradução de poesia, destacando-se como um tema bastante recente nos ETILS, mas com ocorrências em outras revistas também, como na revista In-traduções, em que foi registrada a tradução de poemas e elementos do processo tradutório. Nas revistas Traduzires e Sciencia Traductionis, não foi registrada nenhuma publicação que envolvesse a área de ETILS.

Outra constatação que emerge a partir do índice de publicaçóes registradas refere-se à expansão das pesquisas sobre ETILS enunciada por pesquisadores nacionais e internacionais filiados a diferentes instituiçóes. Do total de trinta e seis artigos analisados, as instituições com maior ocorrência são: Universidade Federal de Santa Catarina, seguida da Universidade Estadual do Ceará, da Universidade Federal de Santa Maria e da Pontifícia Universidade Católica do Rio de Janeiro e Pontifícia Universidade Católica de São Paulo. ${ }^{4}$

4 É importante frisar que as análises aqui constatadas referem-se às datas (anos) em que os artigos foram publicados. Não foi analisada a filiação dos pesquisadores (que outrora eram mestres ou alunos de doutorado e que atualmente estão vinculados às diferentes instituições de ensino). 
O destaque das produçóes registradas nessas revistas concentra-se na Região Sul, Regiấo Nordeste e Regiấo Sudeste, nesta ordem.

As Regióes Norte e Centro-Oeste não foram identificadas nas revistas analisadas neste trabalho. Por outro lado, quatro países estão representados nas publicaçôes, a saber: Universidade Gallaudet e Eastern Kentucky University (Estados Unidos), Macquarie University (Austrália), Escola Superior de Tecnologia e Gestão do Instituto Politécnico de Leiria (Portugal) e Universidade Autonoma de Barcelona (Espanha). As línguas nas quais esses artigos internacionais foram apresentados foram: inglês e português brasileiro (PB). O artigo publicado em Português Brasileiro foi traduzido por Saulo Xavier de Souza, conforme identificado ao final daquele trabalho.

Constatamos também a menção de alguns pesquisadores sobre à filiação a grupos de pesquisa, entre eles destaca-se o Grupo Tradução, Mídia e Audiodescrição - TRAMAD, vinculado à Universidade Federal da Bahia, formado em 2004 e liderado atualmente pela professora Manoela Cristina Correia Carvalho da Silva. Embora tenhamos vários artigos publicados na Cadernos de Tradução, a menção a grupos de pesquisas é quase inexistente nessa revista. Tornar visível a identificação institucional do autor ou dos grupos de pesquisas dos quais ele participa, proporciona a circulação de espaços que respaldam e congregam pares que discutem a temática de ETILS e retrata as diferentes perspectivas existentes sobre os temas investigados.

A tendência é de que a área ETILS seja alavancada nas revistas analisadas, pois dois fatos contribuem bastante para essa questão, sendo a primeira delas: (i) a implementação de cursos de graduação em Tradução e Interpretação de Português-Libras em universidades federais brasileiras, o que propiciará aos ETILS um corpo docente e de pesquisadores que socializarão seus resultados de pesquisas. Além disso, (ii) o aumento de alunos ingressantes nos programas de pós-graduação em Estudos da Tradução, como exemplo, no POSTRAD, PGET e POET, cujo foco seja ETILS, favorece o aumento de publicaçóes e a circulação de temáticas que se articulam aos Estudos da Tradução.

Nesse sentido, uma das açóes importantes é que os programas de pós-graduação em Estudos da Tradução considerem a produção acadêmica de discentes, no intuito de que tenham assegurado espaços onde possam socializar seus trabalhos em parceria com seus orientadores. Ainda que a revista In-Traduçôes tenha registrado apenas dois artigos sobre ETILS, um dos propósitos 
desse periódico é justamente fomentar a produção acadêmica de discentes de diferentes instituições nacionais e internacionais.

Por outro lado, entender algumas das açôes nacionais que colaboraram para a institucionalização da área ETILS e possibilitaram uma constituição identitária mais consolidada é de fundamental relevância para o campo. $\mathrm{Na}$ figura 2, constataram-se os períodos históricos com maior grau de incidência das publicaçóes.

Figura 2: Histórico de artigos por período (1990 a 2014)

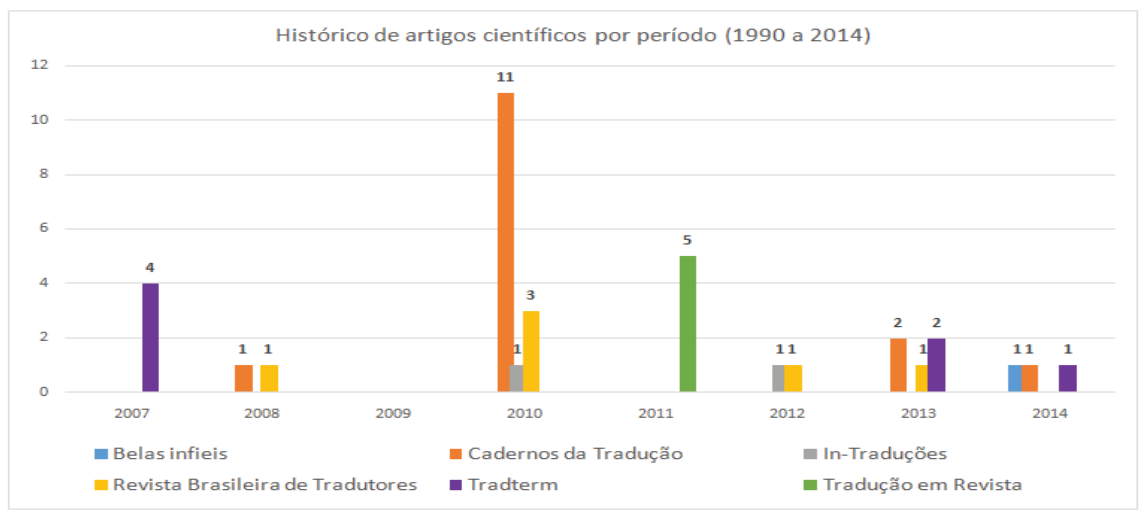

Fonte: próprios autores

Uma das primeiras revistas, das quais temos registros que contém artigos na área de ETILS, refere-se à revista Tradterm, a qual publica um conjunto de quatro artigos que compóem temáticas como legendagem para telenovelas cuja audiência seja o público surdo e audiodescrição (Josélia Neves, Pilar Orero, Ana Ballester Casado e Eliana Paes Cardoso Franco), ratificando a presença das pesquisas internacionais, de países como Espanha e Portugal, além daquelas realizadas no contexto brasileiro.

Este conjunto de textos está inserido em uma edição especial sobre Tradução Audiovisual (TAV), composta por treze artigos e organizada pelas professoras Dra. Eliana Paes Cardoso Franco e Dra. Vera Lúcia Santiago. Franco (2007) salienta a evolução e consolidação das pesquisas em TAV no país, constata a recente emergência dessa área articulada aos Estudos da Traduçáo, ratifica a importância desse campo e dos desafios encontrados no que tange 
à formação e chama atenção sobre a visibilidade que a TAV tem dedicado às pesquisas cujo público seja composto por surdos ou deficientes audiovisuais.

Outro fator que contribuiu para as reflexôes nessa área e produção de pesquisas foi o surgimento de diversas leis que deliberaram sobre a necessidade de recursos visuais destinados às pessoas com deficiência auditiva na veiculação de propaganda oficial e as que instituíram a obrigatoriedade de inserção, nas peças publicitárias em emissoras de televisão, da interpretação da mensagem em legenda e na Libras. É curioso observar que a incidência de artigos de uma determinada área pode variar conforme o espaço em que são publicados. Um exemplo disso refere-se ao fato de que a TAV circulou em revistas da área de Estudos da Tradução por meio dessa edição especial na Tradterm, mas não se obteve o mesmo êxito nos mapeamentos de autores como Santos (2013), Vasconcellos (2010) e Pereira (2010).

Por outro lado, no ano de 2008, embora tenhamos um número reduzido de artigos publicados sobre ETILS, a expansão das revistas que registraram tais materiais foi maior, a saber: Revista Brasileira de Tradutores e Cadernos de Tradução com temáticas como TAV (modelo de legendagem no Brasil para surdos), produzido pela pesquisadora Vera Lúcia Santiago Araújo e as especificidades da interpretação de língua de sinais pela pesquisadora Maria Cristina Pires Pereira. É possível constatar novamente a temática da TAV nos artigos publicados, o que demonstra ser um tema que circula em diferentes periódicos especializados sobre traduçáo, mas pouco trabalhado nos currículos de formação de tradutores de maneira geral e de intérpretes de Libras-Português. Embora Araújo (2006) alerte que:

Os resultados destas pesquisas ainda não chegaram aos profissionais da área, apesar de essas pesquisas levarem em conta o contexto em que a tradução é realizada. Então, todo pesquisador nessa área precisa conhecer as condiçóes de produção das legendas para poder analisá-las. Um aspecto importante a ser considerado é o processo de legendagem (ARAÚJO, 2006, p. 1).

No ano de 2009, não se obteve nenhum registro nas revistas analisadas, diferentemente do ano de 2010, no qual a produção de artigos publicados am- 
pliou-se de tal forma a somar quinze materiais, distribuídos da seguinte forma: 11 artigos de pesquisadores nacionais e internacionais (Thays Fleury Avelar, Maria Cecilia de Moura, Kathryn M. Pacheco Harrison, Neiva de Aquino Albres, Silvana Nicoloso, Marianne Stumpf, Ronice Müller de Quadros, Silvana Aguiar dos Santos, Maria Lúcia Vasconcellos, Maria Cristina Pires Pereira, Melanie Metzger, Jemina Napier e Karen Petronio), registrados nos Cadernos de Tradução; três artigos registrados na Revista Brasileira de Tradutores, das pesquisadoras Maria Cristina Pires Pereira; Ana Claudia Balieiro Lodi, Elomena Barbosa de Almeida e Audrei Gesser; e um artigo, na revista In-traduçôes das pesquisadoras Silvana Nicoloso e Viviane Maria Heberle

Nesse ano de 2010, foi possível constatar uma circulação maior de trabalhos oriundos de pesquisas de mestrado ou de doutorado, afiliadas a diferentes programas de pós-graduação ou, ainda, trabalhos registrados em coautoria de orientandos e seus orientadores. No entanto, destacamos que a grande evidência dos trabalhos concentrou-se na Região Sul do país, já que três revistas analisadas pertencem ao PGET (Cadernos de Tradução, In-Traduçôes e Scientia Traductions). Um dos fatos que contribuiu para a visibilidade de ETILS nessa revista foi o Projeto Interprogramas, o qual tinha como objetivo principal ampliar os espaços de discussão e de desenvolvimento, o aumento de quadro de pesquisadores e de investigaçóes produzidas em torno da Libras. Com relação ao Interprogramas, Quadros (2014) informa que:

A Universidade Federal de Santa Catarina já implementou algumas das açóes previstas no referido decreto, dentre elas os cursos de licenciatura e bacharelado em Letras Libras. No entanto, percebeu a necessidade de formar pesquisadores na área para expandi-la. A partir disso, foi criado o programa em 2007 e realizada a primeira seleção em três programas de Pós-Graduação vinculados ao Centro de Comunicação e Expressão: Programa de Pós-Graduação em Linguística, Programa de Pós-Graduaçấo em Estudos da Tradução e Programa de Pós-Graduação em Literatura. Neste ano, mais um Programa de Pós-Graduação aderiu ao projeto: o Programa de Pós-Graduação em Educação, cuja previsão de vagas é para a próxima seleção. Este projeto alcança diferentes programas de 
pós-graduação para Letras Libras EAD que sejam ampliados os campos de investigação envolvendo a língua brasileira de sinais, a tradução e interpretação dessa língua e a educação de surdos (QUADROS, 2014, p. 23-24).

As temáticas constatadas no ano de 2010, nas três revistas mencionadas anteriormente, não se repetem no ano posterior. No ano de 2011, registramos um total de cinco artigos publicados pela Tradução em Revista cuja temática era sobre TAV, dos pesquisadores Carolina Selvatici; Vera Lúcia Santiago Araújo \& Ana Katarinna Pessoa do Nascimento; Larissa Costa \& Maria Paula Frota; Eliana P. C. Franco \& Vera Lúcia Santiago Araújo e Eliana P. C. Franco, Sandra R. Rosa Farias, Íris Fortunato \& Manoela Cristina da Silva. A circulação dos pesquisadores mencionados acima, assim como as temáticas que envolvem a TAV e sua articulação nos Estudos da Tradução é bastante acentuada. Ao recorrermos aos anais do X Encontro Nacional de Tradutores e IV Encontro Internacional de Tradutores, verificamos que a TAV apresentou várias comunicações de pesquisa. $\mathrm{Na}$ apresentação da temática intitulada "Tradução Audiovisual", as coordenadoras Vera Santiago e Eliana Franco propóem5: "[...] relatar pesquisas recentes no que se refere à acessibilidade em tradução audiovisual [...], área de grande interesse atual, bem como promover o diálogo entre estudiosos e profissionais sobre a prática e o treinamento em tradução audiovisual no país e no exterior" (SANTIAGO e FRANCO, 2009, p. 1).

Aliar pesquisas teóricas e conhecimentos aplicados à prática torna-se fundamental para criar, problematizar e propor diretrizes no ensino de tradutores e intérpretes de Português-Libras em campos especializados do saber. A perspectiva generalista de atuação desse profissional em diversas áreas demanda uma série de sistematizaçóes, tanto na pesquisa, quanto na atuação de cunho prático.

Nesse sentido, considerando o ano de 2012, nas revistas In traduçóes e Revista Brasileira de Tradutores, artigos, respectivamente de autoria de Aline Miguel da Silva e Vinícius Nascimento, contribuíram com temáticas que tratam de processos de tradução literária e consideraçóes dialógicas sobre a interpretação da Libras para o Português na modalidade oral. Aos poucos,

5 A descrição e apresentação das mesas redondas e respectivos participantes encontram-se no site: http://www.nastrilhasdatraducao.ufop.br/traducaoaudiovisual.html 
constatamos uma emergência de novas temáticas de investigação dentro dos ETILS, a partir dessas publicaçóes. Portanto, desconstrói-se a ideia de que nos ETILS há uma homogeneidade de temáticas a serem pesquisadas, pois essas publicaçóes analisadas mostram a diversidade dos temas investigados em um período de 1990 a 2014.

A tendência no ano de 2013 refere-se ao registro de três artigos publicados em diferentes revistas: Tradterm, Cadernos de Tradução e Revista Brasileira de Tradutores. Na Tradterm, a temática tratada foi legendagem para surdos e ensurdecidos de autoria de Vera Lúcia Santiago Araújo; Patrícia Araújo Vieira; Silvia Malena Modesto Monteiro. Nos Cadernos de Tradução, temos temáticas como: "Interpretação educacional como campo de pesquisa: estudo bibliométrico de publicaçóes internacionais e suas marcas no campo nacional”, de autoria das pesquisadoras Neiva de Aquino Albres e Cristina Broglia Feitosa de Lacerda; "Densidade de informaçâo, complexidade fonológica e suas implicaçóes para a organização de glossários de termos técnicos da língua de sinais brasileira", dos pesquisadores Janine Soares Oliveira e Markus Johannes Weininger.

A temática constatada na Revista Brasileira de Tradutores denomina-se "Fatores determinantes na tradução/interpretação das línguas de sinais", desenvolvida pelo autor André Luiz Balan. É possível constatarmos não só alguns temas já recorrentes, como o caso da TAV, mas também a emergência de novos campos investigados, a saber: a interpretação educacional (um dos vieses da interpretação comunitária de acordo com Pöchhacker, 2004) e glossários de termos técnicos.

Por fim, no ano de 2014, contabilizamos um total de três publicaçóes, distribuídas da seguinte forma: um artigo publicado na revista Tradterm cujo tema trata de "Gesto, Oralidade, Escritura e Tradução", do pesquisador Roberto Mário Schramm Junior; um artigo, na revista Cadernos de Tradução sobre "Intérprete surdo de língua de sinais brasileira", de autoria da pesquisadora Ana Regina e Souza Campello; e um artigo na revista Belas Infiéis - "Tradução comentada do poema em Língua Brasileira de Sinais Voo sobre o Rio”, da pesquisadora Marilyn Mafra Klamt.

Portanto, com base nessas discussóes e análise das implicaçóes que atravessam o percurso da área ETILS aliada aos Estudos da Tradução pelo viés das revistas especializadas, apontamos algumas consideraçóes: (i) o de- 
senvolvimento de açóes voltadas à visibilidade dos ETILS, considerando a produção de dossiês temáticos ou volumes especiais em revistas de tradução; (ii) articulação de orientandos e seus orientadores e coorientadores em publicações nacionais de revistas especializadas em tradução; (iii) ações de cunho profissionalizante para visibilidade de pesquisas produzidas com caráter mais aplicado, destinadas à criação de um produto final; (iv) açóes que levem em consideração o incentivo na formação de pesquisadores em ETILS e na visibilidade de publicaçóes em revistas especializadas na área de tradução em diferentes regiōes brasileiras, uma vez que os dados constatam a evidência de trabalhos publicados em revistas das Regiôes Sul e Sudeste; (v) incentivo à criação de novas áreas temáticas, entre elas, a interpretação comunitária e de conferência, uma vez que são temas pouco frequentes nos dados constatados na pesquisa realizada; (vi) formação de pesquisadores e abertura de linhas de pesquisa na subárea dos ETILS em diferentes programas de pós-graduação voltados aos Estudos da Tradução, a exemplo de iniciativas internacionais, nas quais os ETILS estão mapeados como subárea dos Estudos da Tradução.

\section{Considerações finais}

Este trabalho, conforme salientado inicialmente, se comprometeu a descrever e analisar o percurso das publicaçóes sobre tradução e interpretação de Português-Libras em diferentes revistas de Tradução do Brasil no período de 1990 a 2014. Pesquisas dessa natureza são relevantes, a fim de contribuir com os contornos históricos da área, assim como os apontamentos de temas emergentes a partir de análises desse tipo.

Os resultados constatados revelam pouca circulação das produções sobre ETILS nas revistas de tradução e que a maioria das publicações foi registrada após o ano de 2005. Possivelmente, este fato esteja atrelado à regulamentação da lei da Língua Brasileira de Sinais (Libras), no 10436/2002, a qual exigiu dos órgãos governamentais uma série de providências em termos de políticas linguísticas de promoção e difusão da Libras por parte do governo brasileiro. Por outro lado, esses resultados refletem algumas questóes importantes a serem tecidas pelos pesquisadores da área de Letras, Estudos da Tradução e profissionais da área de tradução em geral, dentre elas: 
a) a necessidade de um diálogo nacional mais intenso, no campo da pesquisa entre a subárea ETILS e a área dos Estudos da Tradução, à luz de mapeamentos internacionais já registrados como Williams e Chesterman (2002) e St. Jerome (2008);

b) a ampliação de escopo de objetos de pesquisa tratados nos programas de pós-graduação em Estudos da Tradução, o que, por consequência, pode potencializar a produção acadêmica sobre ETILS;

c) e, por fim, um diálogo mais incisivo, no campo da prática e seu fazer tradutório, entre profissionais da tradução em geral e tradutores e intérpretes de Português-Libras. A articulação desses profissionais, examinando os efeitos de modalidade, os elementos que fazem parte do fazer tradutório, as aproximaçóes e distanciamentos desses profissionais e seus pares linguísticos, pode fomentar a necessidade de formação acadêmica e ampliação do mercado de trabalho. Por exemplo, o corpus analisado neste trabalho constatou que a área TAV tem um destaque significativo no que concerne às articulaçóes com os Estudos da Tradução, e visibiliza também pesquisadores que apresentam uma sólida carreira com produção de destaque nessa interface.

Verificou-se que certas revistas mantêm uma regularidade nas publicações que envolvem ETILS, por exemplo, Cadernos de Tradução, Revista Brasileira de Tradutores seguida da revista Tradterm. Por outro lado, novas áreas se colocam como emergentes, como: a tradução literária e seus processos, a afiliação teórica de ETILS aos Estudos da Tradução, processos de interpretação da Libras para a Língua Portuguesa, entre outros. Além dessas questóes descritivas em relação ao percurso, o presente trabalho buscou elencar, tanto no referencial teórico utilizado quanto na apresentação dos dados, ações que contribuíram para a visibilidade da área ETILS e os desafios que se colocam para esta recente área de pesquisa. Constatou-se que a circulação das pesquisas desenvolvidas no mestrado e doutorado, compreendidas de 1990 a 2010, não constituem alta evidência nessas revistas especializadas de tradução.

Por fim, este artigo não finaliza as discussões sobre a articulação de ETILS e Estudos da Tradução, pelo contrário, ele se apresenta como um material que mapeia percursos do ponto de vista histórico, as problemáticas envolvidas e oferece algumas contribuiçóes para expandir as discussóes nesse campo. É notória a necessidade de discorrer, problematizar e aprofundar 
vários aspectos (ensino e formação de tradutores, intérpretes, pesquisadores, glossários técnicos, contextos comunitários, entre outros) que estão diretamente relacionados ao campo aplicado da tradução e interpretação de língua de sinais.

Sugerem-se mais pesquisas de estado da arte que possam evidenciar a necessidade de um aumento nas publicaçóes da área ETILS, para que esta se firme como área de conhecimento, subsidiando inclusive outras fontes de consulta para os pesquisadores futuros.

\section{Referências}

ALBRES, Neiva. A. As novas tendências metodológicas nos estudos da tradução/interpretação entre o par Português-Libras. In: QUADROS, Ronice Muller de e WEININGER, Markus J. (org.). Estudos da Lingua Brasileira de Sinais III. 1. ed. Florianópolis: Insular, 2014, v. 3, p. 13-34.

ARAÚJO, Vera. L. S. O processo de legendagem no Brasil. Revista do GELNE (UFC), v. 1/2, 1: 156-159, Fortaleza, 2006.

BRASIL. Decreto no 5.626, de 22 de dezembro de 2005. Regulamenta a Lei no 10.436, de 24 de abril de 2002, que dispóe sobre a Língua Brasileira de Sinais - Libras, e o art. 18 da Lei no 10.098, de 19 de dezembro de 2000. Diário Oficial da União, República Federativa do Brasil, Atos do Poder Executivo, DF, n. 246, p. 28-30, 23 dez. 2005, ano CXLII, Seção 1.

. Lei no 10.436, de 24 de abril de 2002. Dispóe sobre a Língua Brasileira de Sinais - Libras e dá outras providências. Diário Oficial da União, República Federativa do Brasil, Atos do Poder Legislativo, DF, n. 79, p. 23, 25 abr. 2002, ano CXXXIX, Seção 1.

CARR et al. The critical link: Interpreters in the community. Papers from the 1st International Conference on Interpreting in Legal, Health, and Social Service Settings, Geneva Park, Canadá, Amsterdam, John postas, June 1-4, 1995.

DIAS, Barbara. C.; FALEIROS, Álvaro. S. A tradução literária em revista no Brasil: aproximaçôes. In: COSTA, Walter Carlos; GUERINI, Andréia; TORRES, Marie-Hélène (Org.). Os Estudos da Tradução no Brasil nos séculos XX e XXI. Florianópolis: PGET/UFSC, 2013, v. 1, p. 191-220.

FERREIRA, Norma Sandra de Almeida. As pesquisas denominadas "estado da arte”. Educaçãođ Sociedade, v. XXIII, 79: 258-272, Campinas, ago. 2002. 
GRBIC, Nadja. Where do we come from? What are we? Where are we going? A bibliometrical analysis of writing and research on Sign Language Interpreting. Sign Language Translator and Interpreter, St. Jerome Publishing, Manchester, 1: 15-51, St. Jerome Publishing, 2007.

MARTINS, Márcia. A. P. As relações nada perigosas entre História, Filosofia e Tradução. Cadernos de Tradução (UFSC), 1: 37-51, Florianópolis, 1996.

METZGER, Melanie. Os destaques das pesquisas sobre interpretação de língua de sinais no contexto acadêmico da interpretação comunitária. Cadernos de Tradução, ediçãao especial - Tradução e Interpretação de Línguas de Sinais, v.2, 26: 13-61, Florianópolis, 2010.

NAPIER, Jemina. An historical overview of signed language Interpreting research: featuring highlights Of personal research. Cadernos de Tradução, edição especial - Tradução e Interpretação de Línguas de Sinais, v.2, 26: 63-97, Florianópolis, 2010.

PAGANO, Adriana. As pesquisas historiográficas em tradução. Metodologias de pesquisa em tradução. Belo Horizonte: Faculdade de Letras, UFMG, 2001. p. 117-146.

PAGANO, Adriana; VASCONCELLOS, Maria Lúcia. Estudos da tradução no Brasil: reflexóes sobre teses e dissertações elaboradas por pesquisadores brasileiros nas décadas de 1980 e 1990. DELTA, Sáo Paulo, v. 19, n. spe, 2003, Acesso em: 30 dez. 2013.

PEREIRA, Maria Cristina Pires. Produções acadêmicas sobre interpretação de língua de sinais: dissertaçóes e teses como vestígios históricos. Cadernos de Tradução, Florianópolis, v. 1, 26: 99-117, Florianópolis, 2010. Acesso em: 30 dez. 2013.

PÖCHHACKER, Franz. Introducing Interpreting Studies, London and New York: Routlegde, 2004.

QUADROS, R. (Org.). Letras Libras ontem, hoje e amanhã. Florianópolis: Editora UFSC, 2014. v. 1. 522p.

QUEIROZ, Mylene. Interpretação médica no Brasil. 2011. 134 p. Dissertação (Mestrado em Estudos da Tradução) - Centro de Comunicação e Expressão, Universidade Federal de Santa Catarina, Florianópolis, 2011.

RODRIGUES, Carlos H. Da interpretação comunitária à interpretação de conferência: Desafios para formação de intérpretes de língua de sinais. II Congresso Nacional de Pesquisa em Tradução e Interpretação de Lingua de Sinais Brasileira, Universidade Federal de Santa Catarina, Florianópolis, 2010. 
RODRIGUES, Cristina C. Os Estudos de Tradução nos programas brasileiros de pós-graduação. In: GUERINI, A.; TORRES, M-H. C.; COSTA, W. C. (Org.). Os estudos da tradução no Brasil nos séculos XX e XXI. Tubarão; Florianópolis: Copiart; PGET/UFSC, 1: 51-69, Tubarão, Florianópolis, 2013.

SANTIAGO, Vera e FRANCO, Eliana. Tradução Audiovisual. Anais do X Encontro Nacional de Tradutores e IV Encontro Internacional de Tradutores, Universidade Federal de Ouro Preto, Ouro Preto, 2009.

SANTOS, Silvana A. dos. Tradução/Interpretação de lingua de sinais no Brasil: uma análise das teses e dissertaçôes de 1990 a 2010, 2013. 313 p. Tese (Doutorado em Estudos da Tradução - Centro de Comunicação e Expressão, Universidade Federal de Santa Catarina, Florianópolis, 2013.

SILVEIRA, Denise T.; CÓRDOVA, Fernanda P. Pesquisa Científica. In: PAGANO, Adriana. Métodos de Pesquisa. Porto Alegre: UFRGS, 2009.

SOUZA, Saulo X. Performances de tradução para a Lingua Brasileira de Sinais observadas no curso de Letras-Libras. Florianópolis, 2010. 174 p. Dissertação (Mestrado em Estudos da Tradução) - Centro de Comunicação e Expressão, Universidade Federal de Santa Catarina, Florianópolis, 2010.

VASCONCELLOS, Maria Lúcia. Tradução e Interpretação de Língua de Sinais (TILS) na Pós-Graduação: a afiliação ao campo disciplinar "Estudos da Tradução". Cadernos de Tradução, Florianópolis, v.2, 26: 119-143, Florianópolis, 2010. Acesso em: 28 dez. 2013.

- Mesa-redonda: A pesquisa em TILS na pós-graduação brasileira: palavras-chave e a questão das filiações teórico-metodológicas. II Congresso Nacional de Pesquisa em Tradução e Interpretação de Lingua de Sinais Brasileira, Universidade Federal de Santa Catarina, Florianópolis, SC. [não publicado], 2010.

WILLIAMS, J \& CHESTERMAN, A. The Map: a beginner's guide to doing research in translation studies. Manchester: St. Jerome Publishing, 2002. 


\title{
THE COURSE OF TRANSLATION AND INTERPRETATION PUBLICATIONS OF BRAZILIAN SIGN LANGUAGE IN SOME BRAZILIAN TRANSLATION JOURNALS
}

\begin{abstract}
This essay describes and analyses the course of publications about Translation and Interpretation of Brazilian sign language in some Brazilian Translation journals. Results show a sum of 36 works published, distributed over Translation journals of different regions of Brazil. The established subjects and the ones that emerged from 1990 to 2014 were also examined in these publications.

KEYWORDS: Translation Studies; Translation and Interpretation Studies of Sign Language; Academic Production.
\end{abstract}

Recebido em: 02/08/2015 Aprovado em: 10/03/2016 